Check for updates

Cite this: RSC Adv., 2017, 7, 32664

Received 25th April 2017

Accepted 22nd June 2017

DOI: $10.1039 / c 7 r a 04641 c$

rsc.li/rsc-advances

\section{An improved enzymatic method for the preparation of $(R)$-phenylacetyl carbinol $\dagger$}

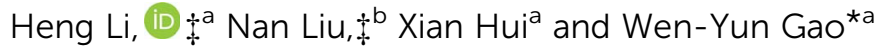

$(R)$-Phenylacetyl carbinol (R-PAC) is one of the key chiral $\alpha$-hydroxyketones utilized as a synthon in the synthesis of a number of pharmaceuticals having $\alpha$ - and $\beta$-adrenergic properties. An improved procedure for the preparation of the compound using the glutathione S-transferase-tag fused catalytic subunit of Escherichia coli acetohydroxyacid synthase I as a catalyst was established in this study. The results showed that under the optimized conditions the target molecule was able to be obtained with an isolated yield of $80.6 \%$ and an ee value of higher than $98 \%$. This method could not only ease the preparation of R-PAC, but promote the synthetic applications of E. coli AHAS I as well.

\section{Introduction}

In both synthetic organic chemistry and medicinal chemistry, chiral $\alpha$-hydroxyketones are always versatile building blocks. $(R)$ Phenylacetyl carbinol ( $R$-PAC) is one of the key chiral $\alpha$-hydroxyketones which has been utilized as a synthon in the synthesis of a number of pharmaceuticals having $\alpha$ - and $\beta$-adrenergic properties, such as L-ephedrine, pseudoephedrine, norephedrine, and phenylpropanolamine. ${ }^{1,2}$ Currently $R$-PAC is manufactured mainly by a fermentation process in which pyruvate decarboxylase (PDC, EC 4.1.1.1), a protein of the yeast cells catalyzing the decarboxylation of pyruvate to form acetaldehyde, accomplishes the condensation of pyruvate with externally supplied benzaldehyde (BA) (Scheme 1).,4 But unfortunately, such biotransformation is quite an ineffective procedure because of its low reaction rate and inefficient conversion of substrates to $R$-PAC. ${ }^{3-5}$ To overcome the problems, researchers have therefore turned to use PDC isolated from different microorganisms as a catalyst to carry out the reaction, but no good result has been obtained. ${ }^{1,2,6-8}$ Bruhn et al. have tried to improve the catalytic characteristics of Zymomonas mobilis PDC (ZmPDC) by means of site-directed mutagenesis, but the overall conversion of pyruvate to the desired product by the most efficient mutant still remained extremely low. ${ }^{9}$ Tittmann $e t$ al. also prepared some mutants of ZmPDC and found that the mutant ZmPDC-Glu473Gln could almost quantitatively convert pyruvate and BA to $R$-PAC with high stereoselectivity (yield $\sim 98 \%$, ee

${ }^{a}$ National Engineering Research Center for Miniaturized Detection Systems, College of Life Sciences, Northwest University, Xi'an, Shaanxi 710069, China. E-mail: gaowenyun@nwu.edu.cn; Fax: +86 29 88303572; Tel: +86 2988303446 ext. 832

${ }^{b}$ Department of Experimental Surgery, Tangdu Hospital, Fourth Military Medical University, Xi'an, Shaanxi 710038, China

$\dagger$ Electronic supplementary information (ESI) available: HPLC analysis, ${ }^{1} \mathrm{H}$, ${ }^{13} \mathrm{C}-\mathrm{NMR}$ and HRESI-MS spectra of $R$-PAC are available. See DOI: $10.1039 / \mathrm{c} 7 \mathrm{ra0} 0464 \mathrm{c}$

$\ddagger$ The first two authors contributed equally to this work.
98.4\%). But the drawback of the mutant was yet its low catalytic efficiency because it needed about 40 hours to finish the transformation, ${ }^{10}$ which might imply that the essential properties of this protein were not suitable for this kind of carboligation.

Acetohydroxyacid synthase (AHAS, EC 2.2.1.6) is a thiamine diphosphate (ThDP) dependent enzyme that has been involved in the biosynthesis of the physiologically significant molecules-the branched-chain amino acids including valine, leucine, and isoleucine. ${ }^{11-13}$ Furthermore, just like PDC, AHAS can also mediate the additional $\mathrm{C}-\mathrm{C}$ bond formation reaction which occurs in competition with acetolactate synthesis, the condensing reaction between pyruvate and BA to generate the chiral-hydroxyketone $R$-PAC (Scheme 1)..$^{14-17}$

Up to now, three different AHAS isozymes (I, II, and III) have been elucidated in enterobacteria such as Escherichia coli, ${ }^{12,18}$ and AHAS I has been proved to be the most ideal target to catalyze the ligation between pyruvate and BA because of its high substrates utilization, high yield of the desired product ( $\sim 87 \%)$, and high ee value ( $\sim 98 \%)$. Meanwhile, AHAS I can tolerate BA at relatively high concentration (about $70-80 \mathrm{mM}$ ), is

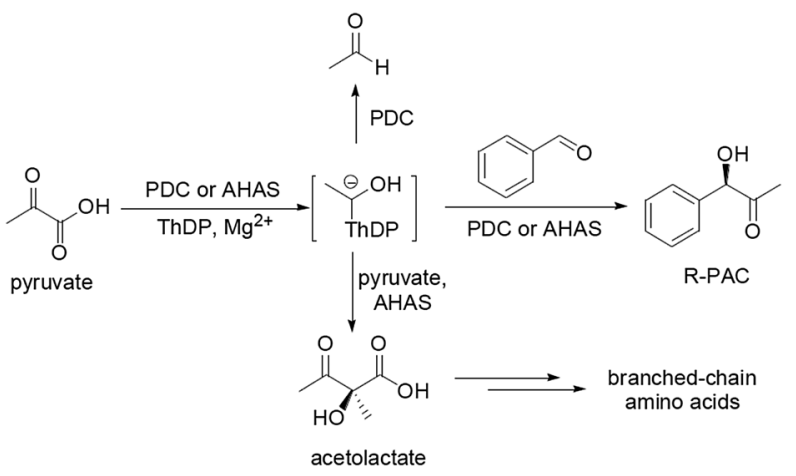

Scheme 1 Enzymatic reactions catalyzed by PDC and AHAS. 


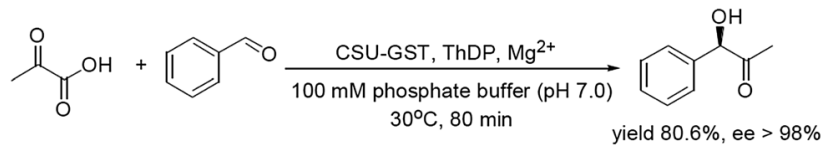

Scheme 2 Enzymatic preparation of R-PAC using CSU-GST of E. coli AHAS I as a catalyst.

not sensitive to the feedback inhibition of the product $R$-PAC, and has a broad spectrum of substrates. ${ }^{14,15}$ But this protein has its own shortcomings. Research has shown that the natural abundance of AHAS is low and its stability is poor. ${ }^{19,20}$ It consists of two homodimers, one of which comprises two catalytic subunits (CSU) that contain the full catalytic machinery to perform the chemical reaction; the other contains two regulatory subunits (RSU) which are necessary for stabilization and regulation of the CSU. ${ }^{11}$ Although it has been reported that the CSU of E. coli AHAS I is active, its activity is very weak in the absence of the RSU. ${ }^{18,20,21}$ In addition, the CSU alone is even more unstable than AHAS I. ${ }^{18-20}$ These traits of AHAS I not only make it difficult to be prepared, but also hinder its application in organic synthesis. This might be the reasons that this protein is not commercial up to date as well.

In one of our projects we prepared the CSU of E. coli AHAS I with histidine-tags (CSU-His) and found that its activity was low and stability was indeed poor. But further experiments exhibited that when the histidine fusion tag was replaced by a glutathione S-transferase (GST) tag, the resulted protein (CSU-GST) showed not only excellent stability, but also high activity. ${ }^{12}$ Moreover, CSU-GST could mediate the condensation between pyruvate and $\mathrm{BA}$ to generate $R$-PAC as well. We thus extended the application of the protein to the synthesis of the chiral $\alpha$ hydroxyketone by optimizing its reaction conditions and evaluating it enantioselectivity (Scheme 2).

\section{Experimental}

\subsection{General}

Unless otherwise noted, all chemicals were purchased from commercial suppliers and used without further purification. Proton-NMR spectrum was recorded at ambient temperature on a Varian Inova-600 MHz NMR spectrometer. The NMR experiment was reported in $\delta$ units, parts per million (ppm), and was referenced to $\mathrm{CDCl}_{3}(\delta 7.26 \mathrm{ppm})$. High-resolution mass spectrum (ESI-MS) was obtained using a Thermo Fisher LTQ XL system spectrometer. Optical rotations were measured on a polarimeter. Column chromatography was performed using silica gel (100-200 mesh).

\subsection{The procedure for synthesis of CSU-GST protein}

The protein was synthesized according to the published procedure with minor modification. ${ }^{22}$ The recombinant plasmid pGEX-4T-1-ilvB was transformed into E. coli BL21(DE3) strain for protein production. Protein expression was induced in $\mathrm{LB}$ medium containing $100 \mu \mathrm{g} \mathrm{mL} \mathrm{m}^{-1}$ ampicillin by addition of $0.5 \mathrm{mM}$ IPTG at mid-log phase at $30^{\circ} \mathrm{C}$ for approximately $6 \mathrm{~h}$ till the $A_{600}$ of the bacterial culture reached 0.5-0.6. Bacteria were harvested (about $3.0 \mathrm{~g} \mathrm{~L}^{-1}$ ), lysed and the CSU-GST protein was obtained after purification on Glutathione Sepharose 4B resin in a yield of $1.5 \mathrm{mg} \mathrm{L}^{-1}$ medium. It was then aliquoted into $0.5 \mathrm{~mL}$ Eppendorf tubes, flash-frozen, and stored at $-80{ }^{\circ} \mathrm{C}$ for later use.

\subsection{The procedure for enzymatic preparation of $R$-PAC}

The reaction mixture comprised of $100 \mathrm{mM}$ phosphate buffer, $5.0 \mathrm{mM} \mathrm{MgCl}$, $1.0 \mathrm{mM}$ ThDP, $0.5 \mathrm{mM}$ dithiothreitol, $6 \%$ DMSO, $40 \mathrm{mM} \mathrm{BA}$, and $100 \mathrm{mM}$ pyruvate in a total volume of $0.5 \mathrm{~mL}$. After mixed well, $0.30 \mathrm{mg} \mathrm{mL}^{-1}$ CSU-GTS was added and the reaction mixture was incubated at $30{ }^{\circ} \mathrm{C}$ for $80 \mathrm{~min}$. Then the mixture was treated in a boiling water bath for $2 \mathrm{~min}$ before it was centrifuged at $10000 \mathrm{rpm}$ for $3 \mathrm{~min}$. The supernatant was extracted three times with $\mathrm{CHCl}_{3}(1.0 \mathrm{~mL} \times 3)$ and the extracts were pooled, back washed twice with brine, and dried over about $0.5 \mathrm{~g}$ anhydrous $\mathrm{MgSO}_{4}$. After removal of the drier through filtration, the resulting solvent was removed under reduced pressure. The residue was subsequently isolated on a silica gel column $(1.0 \times 10 \mathrm{~cm}, 10 \mathrm{~g}$ silica gel $)$ developed by petrol ether-ethyl acetate $(3: 1)$. The fractions containing the target molecule were combined and solvent was removed in vacuum. The white powder generated ( $c a .9 .67 \mathrm{mg}$, yield 80.6\%, ee $>98 \%$ ) was further elucidated by optical rotation, HRESI-MS, ${ }^{1} \mathrm{H}$ - and ${ }^{13} \mathrm{C}-\mathrm{NMR}$. The purity of the product $(>98 \%)$ was evaluated by the HPLC method described below.

\subsection{The HPLC method}

The HPLC analyses of the reactions and the product were performed on an Aglient 1200 HPLC system, equipped with an autosampler with a $50 \mu \mathrm{L}$ loop and a diode array spectrometer. Separation was carried out on an Agilent RP-18 column $(250 \times$ $4.6 \mathrm{~mm}, 5 \mu \mathrm{m}$ ) with $30 \%$ aqueous acetonitrile as a mobile phase, at a detection wavelength of $280 \mathrm{~nm}$, a flow rate of $0.7 \mathrm{~mL}$ $\min ^{-1}$, and ambient temperature. The ee value of the reaction was measured using the reported method ${ }^{23}$ on a chiral column Chiralcel OD-H $(250 \mathrm{~mm} \times 4.6 \mathrm{~mm}, 5 \mu \mathrm{m})$ at $25{ }^{\circ} \mathrm{C}$ and a flow rate of $0.7 \mathrm{~mL} \mathrm{~min}^{-1}$. The mobile phase used was $n$-hexane/2propanol $=90: 10$. The UV detection wavelength was set at $280 \mathrm{~nm}$.

$(R)$-Phenylacetyl carbinol (R-PAC). White powder, $9.67 \mathrm{mg}$, $80.6 \%$ yield. $[\alpha]_{\mathrm{D}}^{20}=-177^{\circ}$ (c 1.6, MeOH). ${ }^{1} \mathrm{H}-\mathrm{NMR}(600 \mathrm{MHz}$, $\left.\mathrm{CDCl}_{3}\right) \delta 2.09(\mathrm{~s}, 3 \mathrm{H}, \mathrm{Me}), 4.29(\mathrm{~d}, J=3 \mathrm{~Hz}, 1 \mathrm{H}, \mathrm{OH}), 5.09$ (d, $J=$ $3 \mathrm{~Hz}, 1 \mathrm{H}, \mathrm{CH}), 7.32-7.39$ (m, 5H, aromatic); ${ }^{13} \mathrm{C}-\mathrm{NMR}(100 \mathrm{MHz}$, $\left.\mathrm{CDCl}_{3}\right) \delta 25.391\left(\mathrm{CH}_{3}\right), 80.224(\mathrm{CH}), 127.455$ (aromatic $\left.\mathrm{CH} \times 2\right)$, 128.765 (aromatic $\mathrm{CH}$ ), 129.164 (aromatic $\mathrm{CH} \times 2$ ), 137.979 (aromatic CH), $207.208(\mathrm{C}=\mathrm{O})$; HRMS (ESI) (negative mode) $\mathrm{m} / \mathrm{z}:[\mathrm{M}-\mathrm{H}]^{-}$found $149.0605, \mathrm{C}_{9} \mathrm{H}_{9} \mathrm{O}_{2}$, requires 149.0603 .

\section{Results and discussion}

\subsection{Optimization of the reaction conditions}

In order to maximize the production of $R$-PAC, we optimized the reaction conditions by altering $\mathrm{pH}$ value, reaction buffer, reaction temperature, amount of CSU-GST, concentration of DMSO 
(as a co-solvent), and the molar ratio of pyruvate to BA. Generation of $R$-PAC was monitored using the HPLC method described in the experimental section and each experiment was repeated three times to avoid accidental error. All the results were exhibited in Fig. 1. Panel A displayed the dependency of the $R$-PAC production on the $\mathrm{pH}$ of the reaction mixture. Four $\mathrm{pH}$ values were tested and the results indicated that $\mathrm{pH} 7.0$ was the best for the activity of CSU-GST. This optimum $\mathrm{pH}$ is identical with that of the $E$. coli AHAS I in mediating the same condensation reaction. ${ }^{\mathbf{1 4}}$ Because it has been observed that the activity of the CSU of $E$. coli AHAS I and the stability of CSU-GST largely related to the buffers used, ${ }^{\mathbf{1 3 , 2 2}}$ we assessed the influence of different buffers on the yields of $R$-PAC. The data (panel B) showed that among the four normally used buffers, namely tris(hydroxymethyl)aminomethane-HCl (Tris-HCl), 4-(2hydroxyethyl)-1-piperazineethanesulfonic acid (HEPES), phosphate buffer (PB), and 3-( $N$-morpholino)propanesulfonic acid (MOPS), PB buffer gave the highest $R$-PAC yield. This observation suggested that the CSU of AHAS I might really favor a phosphate buffer. In panel $\mathrm{C}$ we determined the impact of temperature on the production of $R$-PAC and found that the reaction carried out at $30{ }^{\circ} \mathrm{C}$ led to the most desired product. This optimum reaction temperature of CSU-GST is in correspondence to that of the $R$-PAC formation reaction catalyzed by of $E$. coli AHAS I. ${ }^{14}$ Panel D depicted the effect of the amount of the enzyme on the generation of $R$-PAC, from which we were able to find that when CSU-GST reached $0.15 \mathrm{mg}$, the highest production of $R$-PAC could be obtained. Thus $0.15 \mathrm{mg}$ of the protein was selected as the optimum enzyme amount. In the next experiments, we separately discussed the dependency of the $R$-PAC generation on the DMSO concentration and on the $\mathrm{BA}$ to pyruvate ratio. Because $\mathrm{BA}$ is insoluble in water, we have to use DMSO as a co-solvent to enhance its solubility. From panel E we could find that too low $(<4 \%)$ or too high $(>10 \%)$ DMSO content would retard the formation of the desired product. Too low DMSO concentration might not be enough to solubilize BA, while too high DMSO concentration might be adverse to the enzyme, so $6 \%$ was selected as the optimum DMSO content. Panel $\mathrm{F}$ gave the influence of the BA to pyruvate ratio on the production of $R$-PAC. It is noteworthy that only when the excess of pyruvate attained $150 \%$, maximum yield of $R$-PAC would be expected. This is same as in the $R$-PAC production reaction mediated by $E$. coli AHAS I. ${ }^{\mathbf{1 4}}$ The significant pyruvate excess needed in the $R$-PAC production might reflect that the formation of $R$-PAC has to compete with the formation of acetolactate, the natural product of AHAS catalysis. Based on the above measurements, we established the optimum conditions for CUS-GST reaction: the synthesis of $R$-PAC ought to be carried out with $0.30 \mathrm{mg} \mathrm{mL}^{-1} \mathrm{CSU}-\mathrm{GTS}$ at $30{ }^{\circ} \mathrm{C}$ for $80 \mathrm{~min}$, in $0.5 \mathrm{~mL}$ of $100 \mathrm{mM}$ phosphate buffer (pH 7.0), containing $5.0 \mathrm{mM}$ $\mathrm{MgCl}_{2}, 1.0 \mathrm{mM}$ ThDP, $0.5 \mathrm{mM}$ dithiothreitol (DTT), 6\% DMSO, $40 \mathrm{mM} \mathrm{BA}$, and $100 \mathrm{mM}$ pyruvate.

The enzymatic reaction mixture contained $100 \mathrm{mM}$ phos-

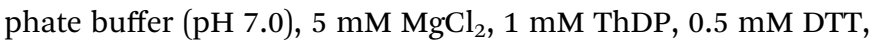
$100 \mathrm{mM}$ pyruvate, $40 \mathrm{mM}$ BA, 6\% DMSO, and $0.15 \mathrm{mg}$ CSU-GST in a volume of $500 \mu \mathrm{L}$ and the reaction was carried out at $30{ }^{\circ} \mathrm{C}$
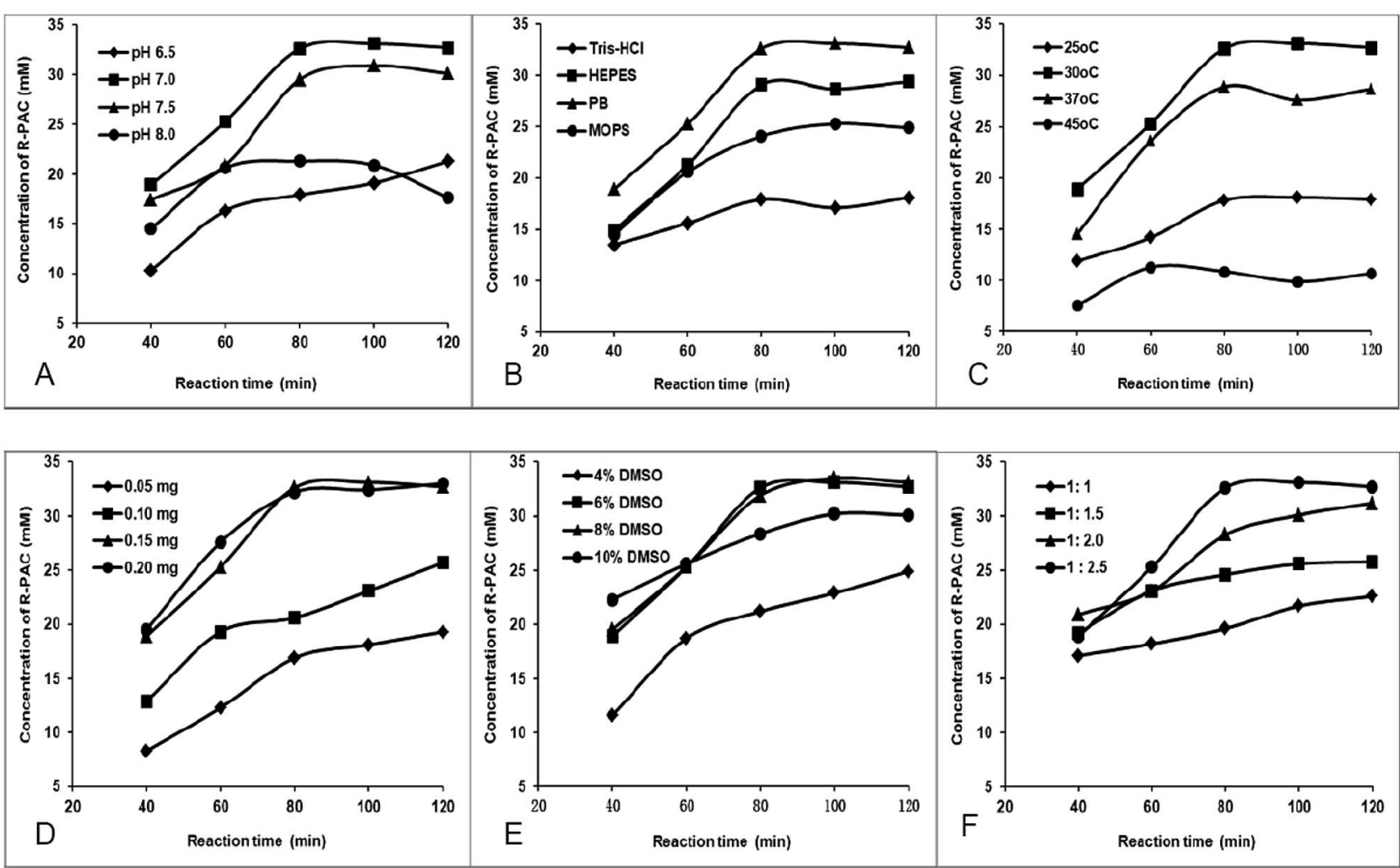

Fig. 1 Optimization of the enzymatic production of $R$-PAC. 
for $120 \mathrm{~min}$. (A) $\mathrm{pH}$ dependency at $30{ }^{\circ} \mathrm{C}$; (B) buffer $(100 \mathrm{mM})$ dependency at $30^{\circ} \mathrm{C}$ and $\mathrm{pH} 7.0$; (C) temperature dependency at pH 7.0; (D) CSU-GST dependency at $30^{\circ} \mathrm{C}$ and pH 7.0; (E) DMSO concentration dependency at $30^{\circ} \mathrm{C}$ and $\mathrm{pH} 7.0$; (F) BA to pyruvate ratio dependency at $30{ }^{\circ} \mathrm{C}$ and $\mathrm{pH} 7.0$ (40 mM BA).

\subsection{Determination of BA tolerance of the protein CSU-GST}

Because a high BA concentration could be adverse to the enzyme, ${ }^{14}$ we determined the BA tolerance of the protein CSUGST. Both of the formation of $R$-PAC and the consumption of BA were monitored by the HPLC method. The results of the BA tolerance experiments, as depicted in Fig. 2, showed that at a pyruvate concentration of $100 \mathrm{mM}$, the enzyme CSU-GST attained its highest catalytical efficiency when the concentration of BA reached $40 \mathrm{mM}$ with an $R$-PAC yield of about $83 \%$ and a BA conversion of about $90 \%$. With the further increase of BA, the catalytical efficiency of the protein began to decrease, for example, at $50 \mathrm{mM}$ BA the yield of $R$-PAC was around $68 \%$ and the conversion of BA was around $83 \%$. Therefore, the maximum

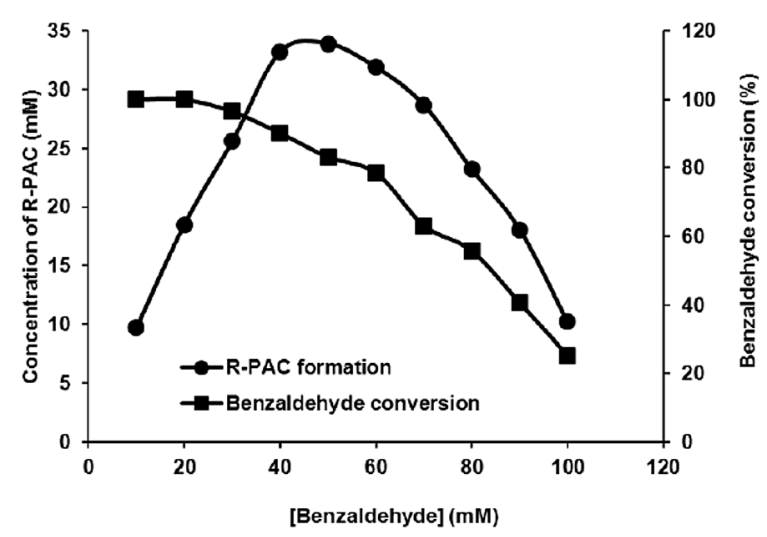

Fig. 2 BA tolerance of CSU-GST. Reactions were carried out as for Fig. 1 with $100 \mathrm{mM}$ pyruvate and varied concentrations of BA. The formation of R-PAC (-) and the conversion of BA (ם) were determined by the HPLC method after 80 min incubation.

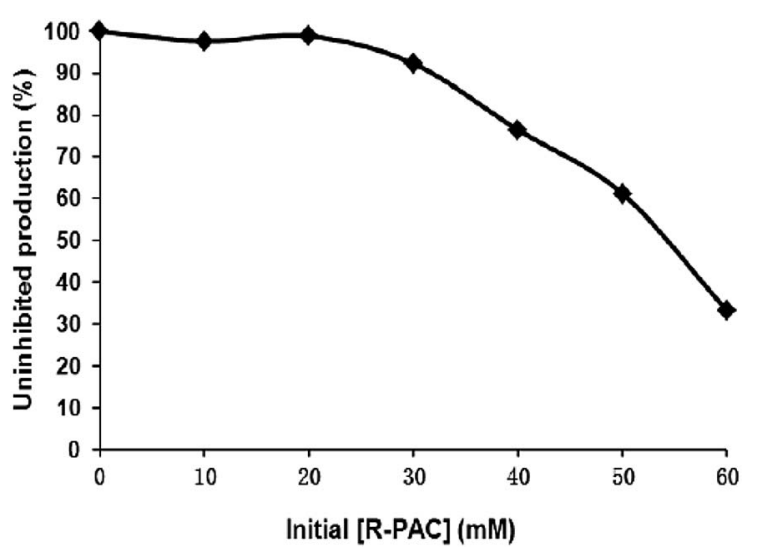

Fig. 3 The feedback inhibition of $R$-PAC on CSU-GST. The reactions were carried out for $80 \mathrm{~min}$ as described in Fig. 1 in the presence of $R$ $\mathrm{PAC}$ at different concentrations. The formation of $R$-PAC was determined by the HPLC method.
BA that was able to be used in the CSU-GST reaction was $40 \mathrm{mM}$ and higher BA contents would be deleterious to the protein.

\subsection{Measurement of the $R$-PAC feedback inhibition on CSU- GST}

The product feedback inhibition on CSU-GST was also measured by adding different amounts of $R$-PAC to the reaction mixtures before the reaction was initialized. The total $R$-PAC was then analyzed by the HPLC procedure and uninhibited production of $R$-PAC was calculated. It is worth noting that the external $R$-PAC at a concentration lower than $30 \mathrm{mM}$ would not significantly affect the yield of the reaction, which means that the protein CSU-GST is not sensitive to the $R$-PAC feedback inhibition (Fig. 3).

\subsection{Preparation of $\boldsymbol{R}$-PAC under optimized conditions}

With the optimized process, we prepared $R$-PAC in two parallel reactions. After worked up, the target compound was obtained as white powder with an isolated yield of over $80 \%$ (purity $>98 \%$ ) and an ee value of bigger than $98 \%$. Its structure was further elucidated by spectroscopic methods. All the data acquired were identical with the previous reported for $R$-PAC. ${ }^{\mathbf{1 4 , 1 5 , 2 3 , 2 4}}$

\section{Conclusions}

In summary, we established in this study a practical enzymatic procedure to prepare the chiral $\alpha$-hydroxyketone $R$-PAC using the GST-tag fused CSU of E. coli AHAS I as a catalyst. Under the optimized reaction conditions, $R$-PAC was able to be efficiently produced in a good yield and an excellent stereoselectivity. We anticipate that this work could not only facilitate the preparation of $R$-PAC, but promote the synthetic applications of $E$. coli AHAS I as well.

\section{Conflict of interest}

The authors declare no competing financial interest.

\section{Acknowledgements}

This work was supported by the National Science Foundation of China (NSFC) under Grants 21402152 and 21172179; the Program for Changjiang Scholars and Innovative Research Team in University (No. IRT_15R55); the Scientific Research Projects of Shaanxi Province (2017JM2027) and the Education Department of Shaanxi Provincial Government (No. 15JK1710). The authors gratefully acknowledge Dr Xinfeng Zhao and Dr Chaoni Xiao of College of Life Sciences, Northwest University for their kind help in MS and ${ }^{1} \mathrm{H}-\mathrm{NMR}$ analyses.

\section{References}

1 H. Iding, P. Siegert, K. Mesch and M. Pohl, Biochim. Biophys. Acta, 1998, 1385, 307-322.

2 V. B. Shukla and P. R. Kulkarni, World J. Microbiol. Biotechnol., 2000, 16, 499-506. 
3 P. L. Rogers, H. S. Shin and B. Wang, Adv. Biochem. Eng./ Biotechnol., 1997, 56, 33-59.

4 O. P. Ward and A. Singh, Enzyme biotransformation involving $\alpha$-ketoacid decarboxylases, in Microorganisms for Industrial Enzymes and Biocontrol, ed. E. Mellado and J. L. Barredo, Research Signpost, Thiruvananthapuram, Kerala, 2005, pp. 83-94.

5 A. Long, P. James and O. P. Ward, Biotechnol. Bioeng., 1989, 33, 657-660.

6 V. Křen, D. H. G. Grout, H. Dalton, D. W. Hutchinson, W. König, M. M. Turner, G. Dean and N. Thomson, J. Chem. Soc., Chem. Commun., 1993, 341-343.

7 S. Bornemann, D. H. G. Crout, H. Dalton, V. Kren, M. Lobell, G. Dean, N. Thomson and M. M. Turner, J. Chem. Soc., Perkin Trans. 1, 1996, 5, 425-430.

8 O. P. Ward and A. Singh, Curr. Opin. Biotechnol., 2000, 11, 520-526.

9 H. Bruhn, M. Pohl, J. Grötzinger and M. R. Kula, Eur. J. Biochem., 1995, 234, 650-655.

10 D. Meyer, L. Walter, G. Kolter, M. Pohl, M. Müller and K. Tittmann, J. Am. Chem. Soc., 2011, 133, 3609-3616.

11 M. Michael, G. Doerte and P. Martina, FEBS J., 2009, 276, 2894-2904.

12 V. Gedi and M. Y. Yoon, FEBS J., 2012, 279, 946-963.

13 V. I. Bunik, A. Tylicki and N. V. Lukashev, FEBS J., 2013, 280, 6412-6442.
14 S. Engel, M. Vyazmensky, S. Geresh, Z. E. Barak and D. M. Chipman, Biotechnol. Bioeng., 2003, 83, 833-840.

15 S. Engel, M. Vyazmensky, D. Berkovich, Z. E. Barak and D. M. Chipman, Biotechnol. Bioeng., 2004, 88, 825-831.

16 T. Sehl, H. C. Hailes, J. M. Ward, R. Wardenga, E. von Lieres, H. Offermann, R. Westphal, M. Pohl and D. Rother, Angew. Chem., Int. Ed., 2013, 52, 6772-6775.

17 T. Sehl, H. C. Hailes, J. M. Ward, U. Menyes, M. Pohl and D. Rother, Green Chem., 2014, 16, 3341-3348.

18 V. Vinogradov, M. Vyazmensky, S. Engel, I. Belenky, A. Kaplun, O. Kryukov, Z. Barak and D. M. Chipman, Biochim. Biophys. Acta, 2006, 1760, 356-363.

19 H. E. R. B. E. R. T. Grimminger and H. E. Umbarger, J. Bacteriol., 1979, 137, 846-853.

20 L. Eoyang and P. M. Silverman, J. Bacteriol., 1986, 166, 901904.

21 M. Vyazmensky, C. Sella, Z. Barak and D. M. Chipman, Biochemistry, 1996, 35, 10339-10346.

22 H. Li, N. Liu, W. T. Wang, J. Y. Wang and W. Y. Gao, J. Biosci. Bioeng., 2016, 121, 21-26.

23 T. Sehl, R. C. Simon, H. C. Hailes, J. M. Ward, U. Schell, M. Pohl and D. Rother, J. Biotechnol., 2012, 159, 188-194.

24 J. Brussee, E. C. Roos and A. Van Der Gen, Tetrahedron Lett., 1988, 29, 4485-4488. 